\title{
Good practice regarding smoking cessation management in Spain: Challenges and opportunities for primary care physicians and nurses
}

\author{
Carlos Martin-Cantera ${ }^{1,2}$, Jose M. Iglesias Sanmartín ${ }^{3}$, Ana Furió Martínez ${ }^{4}$, Cesar Minué Lorenzo5 ${ }^{5}$ Vidal Barchilón \\ Cohen ${ }^{6}$, Maria L. Clemente Jiménez ${ }^{7}$, Sara Cascón Pérez-Teijón ${ }^{8}$, Joan A. Ribera i Osca ${ }^{9}$, Rodrigo Córdoba Garcia ${ }^{10}$, Joan \\ Lozano Fernández ${ }^{11}$, Miguel A. Gallardo Domenech ${ }^{12}$, Maria A. Mendiguren Navascues ${ }^{13}$, Emilio Salguero Chaves $^{14}$, \\ María L. Rodríguez Ibañez ${ }^{15}$, Victoria Gueto Rubio ${ }^{16}$, Susana Morena Rayo ${ }^{17}$, Bruno Marioni Otero ${ }^{18}$, Lucia Gorreto \\ Lopez $^{19}$, Francisco Camarelles Guillem ${ }^{20}$, Fernando Martín Fuente ${ }^{21}$, Diego Beni Ruiz ${ }^{22}$, Alicia I. Hernández Rodríguez ${ }^{23}$, \\ Juan De Dios González Caballero" ${ }^{24}$ Cruz Bartolomé Moreno ${ }^{25}$, Mercé Pau Pubil25, Merce Lopez Grau²6
}

\begin{abstract}
INTRODUCTION We analyze the activities carried out by primary care (PC) physicians and nurses with respect to smoking cessation and evaluate their self-reported training, knowledge, and behavior.

METHODS A cross-sectional study was conducted including 1514 PC physicians and nurses from June 2016 to March 2017, in Spain. The main variable was Good Practice (GP) in attention to smokers. To identify associated factors, a multilevel logistic regression model was used adjusted for sex, age, type of center, contract, years of employment, tobacco consumption, and self-reported training/knowledge.

RESULTS Of the 792 physicians and 722 nurses, $48.6 \%$ referred to GP in smoking cessation management. The finding related to: being a nonsmoker $(\mathrm{OR}=1.8 ; 95 \% \mathrm{CI}: 1.2-2.5)$ or ex-smoker (OR=1.4; 95\% CI: 1.02-2.1), having a good level of knowledge (OR=1.8; 95\% CI: 1.3-2.4) and training ( $\mathrm{OR}=2.4 ; 95 \% \mathrm{CI}: 1.8-3.2)$, and, to a lesser extent, being female $(\mathrm{OR}=1.3 ; 95 \%$ CI: $1.03-1.7)$, and work experience $>10$ years (OR=1.4; 95\% CI: 1.03-1.9). The main GP barriers were: lack of time (45.5\%), organizational problems (48.4\%), and 35.4\% lack of training. CONCLUSIONS The GP of PC physicians and nurses regarding smoking cessation management is related to being non-smokers or ex-smokers, and having sufficient training and knowledge. Lack of time and organizational problems were considered to be the main barriers. The promotion of training activities in the Spanish National Health Service with the support of scientific societies is required.
\end{abstract}

AFFILIATION

1 Institut Universitari d'Investigació en Atenció Primària Jordi Gol, Barcelona, Spain 2 Grupo Abordaje al Tabaquismo SemFYC, Barcelona, Spain

3 Unidad Especializada de Tabaquismo del Área Sanitaria IV del Principado de Asturias, Asturias, Spain

4 Centro Salud de Serreria, Valencia, Spain 5 Centro Salud Perales del Río, Madrid, Spain 6 Centro Salud Rodríguez Arias, Cádiz, Spain

7 Centro Salud La Jota, Zaragoza, Spain 8 Centro Salud Robleda, Salamanca, Spain 9 Centro Salud de Alcásser, Valencia, Spain 10 Centro Salud de Delicias Sur, Zaragoza, Spain

11 Fundación de Atención Primaria, Barcelona, Spain

12 Centro Salud de Arnedo, La Rioja, Spain 13 Centro de salud Parte Vieja, San Sebastián, Spain

14 Centro Salud Valdepasillas, Badajoz, Spain 15 Centro Salud de Tolosa, Tolosa, Spain 16 Centro Salud Mendillorri, Navarra, Spain 17 Centro Salud de Hellin, Albacete, Spain 18 Centro Salud Redondela, Pontevedra, Spain 19 Centro Salud de Coll d'en Rabassa, Mallorca, Spain

20 Centro Salud Infanta Mercedes, Madrid, Spain

21 Unidad Deshabituación tabáquica SCS, Centro Salud de Vargas, Cantabria, Spain 22 Consultorio de Aldeanueva de Ebro, Centro de Salud Alfaro, La Rioja, Spain

23 Centro Salud de Barranco Grande, Tenerife, Spain

24 Cuidados y Cronicidad del Sistema

Murciano de Salud, Subdirección General de Planificación, Murcia, Spain

25 Unidad Docente MFyC Sector Zaragoza I, Zaragoza, Spain

26 Centre Atenció Primaria Passeig de Sant Joan, Barcelona, Spain 
CORRESPONDENCE TO

Carlos Martin-Cantera. Institut Universitari d'Investigació en Atenció Primària Jordi Gol, (IDIAP Jordi Gol), Gran Via de les Corts Catalanes, 587, 08007 àtic, Barcelona, Spain. E-mail: c.martincantera@gmail.com ORCID ID: https://orcid.org/0000-0003-0656-8126

\section{KEYWORDS}

smoking cessation, attitudes, primary healthcare, clinical competence, surveys and questionnaires, Public Health Practice

Received: 24 May 2020

Revised: 27 July 2020

Accepted: 21 August 2020

\section{INTRODUCTION}

Primary care (PC) physicians and nurses are in an excellent position to help reduce smoking rates through counselling, which has proved to be an efficient and viable strategy. For the general public, which includes an elevated number of smokers, PC staff represent their first medical contact. These professionals are aware of the medical history and social context of their patients who both trust and consider them models to imitate ${ }^{1,2}$.

It has been demonstrated that brief counselling alone only results in a $3 \%$ rate of smoking cessation. In contrast, the recommended strategy of $5 \mathrm{As}$ counselling (Ask about smoking status, Advise the individual to give up, Assess willingness, Assist and Arrange follow-up) together with pharmacologic therapy can triple the result ${ }^{3-6}$.

In order to standardize and rationalize this kind of assistance, some guidelines recommend the use of stages-of-change. A strategy that provides a practical framework with which to classify smokers and predict abstinence at one year ${ }^{7}$.

A recent review of the main PC clinical practice guidelines placed emphasis on identifying smokers, registering their consumption, assessing how motivated they were to give up, offering behavioral and pharmacologic therapy, and evaluating abstinence following treatment. It also recommended specific training to offer such assistance ${ }^{8}$.

Various meta-analyses and reviews have established that in PC, multi-component interventions that combine behavioral support with pharmacologic treatment are the most effective in the $5 \mathrm{As}$ strategy ${ }^{9,10}$. Our group has reported a smoking prevalence in Spain among PC physicians and nurses of $11.8 \%$ and $12.8 \%$, respectively ${ }^{11}$.

The main objective of this study was to analyze the activities carried out by PC physicians and nurses in Spain with respect to smoking cessation management. It included evaluating their training, knowledge, and behavior regarding the issue.

\section{METHODS}

\section{Design and scope}

A multi-center, transversal study was carried out between June 2016 and March 2017. The study population comprised medical and non-medical staff from the PC teams of the Spanish National Health Service.

\section{Sample size}

The sample size $(n=3994)$ was based on $5 \%$ simple random sampling of the PC centers belonging to each autonomous community with an estimated $20 \%$ dropout rate.

\section{Recruitment}

Members of the Smoking Cessation Group (GAT) and the Spanish Family and Community Medical Society (semFYC) created a questionnaire and carried out an ad hoc pilot test. The final version of the questionnaire was designed to be anonymously selfcompleted online. It described the study objectives 
and gave the recipient one month for completion. In order to improve participation, telephone calls and emails were employed. Prior to participation, subjects were informed of the study's objective and that taking part was both voluntary and anonymous.

\section{Variables}

Information was gathered regarding sociodemographic data, PC center location (rural/urban), profession (physician, nurse, office staff etc.), years of employment, and labor status. In addition, details were collected regarding tobacco consumption (habitual/occasional smoker, ex-smoker, never smoker), smoking cessation interventions performed at the PC center, administration of diagnostic and therapeutic measures (use of medication, psychosocial intervention strategies), and training/knowledge regarding the management of smoking.

Opinions were evaluated using Likert scales ( 1 being the least favorable and 5 the most). The statistical analysis was based on agreement of values $\geq 4$.

A complex variable was created - Good Practice (GOLD) with two categories (Good Practice [GP] and Improvable Practice). 'Always' (score 5) and 'Almost Always' (score 4) were considered GP when the PC physician or nurse asked the patients about their smoking habits and consumption, registered this information in their medical record, recommended giving up, advised patients about illnesses related to smoking, asked them if they had smoking-related questions, explained ways to quit if they wanted to, and agreed on a cessation plan if the patient was willing. A rating of $\leq 3$ was considered Improvable Practice.

Although not part of this study, we also inquired about attitudes with respect to smoking and opinions concerning regulations, smoke-free areas and how smokers were affected, and e-cigarette legislation ${ }^{11}$.

\section{Data analysis}

A descriptive analysis was performed (frequencies and percentages of qualitative variables) and a summary one with respect to quantitative variables (means and standard deviations) with a $95 \%$ confidence interval (CI) for both the global sample and study groups. A bivariant analysis was carried out with proportional and mean comparison tests employing non-parametric tests if necessary.

In order to identify variables associated with GP in smoking cessation management, the percentages of any variable that could be explicative was calculated by Pearson chi-squared test. A multi-variant logistic regression model was adjusted. It included significant bi-variables and those considered relevant: sex, age group, location of center, type of contract, years of employment, tobacco consumption, training, and knowledge. Raw (OR) and adjusted odds ratios (AOR) were calculated together with their $95 \%$ CI. Level of significance was $p \leq 0.05$. The SPSS version 17.0 was employed.

\section{RESULTS}

A total of 3965 questionnaires were sent and 2040 (51.5\%) responses obtained, 1514 from PC physicians and nurses, the rest of the sample (516) was basically administrative support personnel, of no interest for this topic. With respect to the first group, the average age was 50.5 years, somewhat higher in physicians than nurses (51.2 and 49.7 years, respectively). Women represented $75.8 \% ; 72 \%$ worked in urban areas, and the number of years employed was 18.3 (20.4 and 16.1 for physicians and nurses, respectively). Most of them had permanent contracts. Almost half the respondents were non-smokers $(49.7 \%), 38.1 \%$ exsmokers, and $12.2 \%$ smokers (daily/occasional) with differences between physicians (11.2\%) and nurses (13.2\%). Slightly more than half $(51.4 \%)$ believed they had enough knowledge to help their patients quit smoking although there were differences between physicians (54.9\%) and nurses (47.5\%). Only 41.5\% had received specific training (Table 1 ).

Tables 2 and 3 show data concerning practice in smoking cessation attention. They are analyzed according to profession, tobacco consumption, and level of knowledge and training. The most frequent activities were Advise, Ask, and Assist, whilst the least frequent was Arrange (follow-up).

We observed differences between nursing and medical staff with respect to registry, explanation of methods, and follow-up agreement. Smokers from both groups gave less advice to their patients about cessation $(\mathrm{p}=0.001)$ and agreed on fewer plans to quit $(p<0.001)$. Subjects who claimed to have sufficient knowledge and skills to help patients give up carried out better practice in relation to smoking 
Table 1. Sociodemographic characteristics, smoking prevalence, and level of training and knowledge among primary care physicians and nurses ( $N=1514)$

\begin{tabular}{|c|c|c|c|c|}
\hline Variables & $\begin{array}{l}\text { Total* } \\
n(\%)\end{array}$ & $\begin{array}{c}\text { Physician } \\
n(\%)\end{array}$ & $\begin{array}{l}\text { Nurse } \\
n(\%)\end{array}$ & $p$ \\
\hline Participants $^{* a}$ & $1514(100)$ & $792(52.3)$ & $722(47.7)$ & \\
\hline Age (years), (mean \pm SD) & $50.51 \pm 9.8$ & $51.2 \pm 9.6$ & $49.74 \pm 9.8$ & 0.004 \\
\hline \multicolumn{5}{|l|}{ Sex, n (\%) } \\
\hline Male & $367(24.2)$ & $260(32.8)$ & $107(14.8)$ & \\
\hline Female & $1147(75.8)$ & $532(67.2)$ & 615 (85.2) & 0.001 \\
\hline \multicolumn{5}{|l|}{ Center, n (\%) } \\
\hline Urban & $1090(72.0)$ & $567(71.3)$ & $523(72.4)$ & \\
\hline Rural & $424(28.0)$ & $225(28.7)$ & $199(27.6)$ & 0.379 \\
\hline Years of employment, $\left(\right.$ mean $\left._{ \pm} \mathrm{SD}\right)$ & $18.39 \pm 10.0$ & $20.46 \pm 9.76$ & $16.10 \pm 9.90$ & 0.001 \\
\hline \multicolumn{5}{|l|}{ Employment status, n (\%) } \\
\hline Permanent & 1271 (83.9) & $681(86.0)$ & $590(81.7)$ & 0.025 \\
\hline Interim & $243(16.1)$ & $111(14.0)$ & $132(18.3)$ & \\
\hline \multicolumn{5}{|l|}{ Smoking status, n (\%) } \\
\hline Non-smoker & $753(49.7)$ & $428(54.0)$ & $325(45.0)$ & \\
\hline Ex-smoker & $577(38.1)$ & $275(34.7)$ & $302(41.8)$ & 0.002 \\
\hline Smoker & $184(12.2)$ & 89 (11.2) & 95 (13.2) & \\
\hline \multicolumn{5}{|l|}{ Sufficient knowledge, n (\%) } \\
\hline Yes & $778(51.4)$ & $435(54.9)$ & $343(47.5)$ & 0.002 \\
\hline No & $736(48.6)$ & $357(45.1)$ & $379(52.5)$ & \\
\hline \multicolumn{5}{|l|}{ Sufficient training, $\mathrm{n}(\%)$} \\
\hline Yes & $629(41.5)$ & $343(43.3)$ & $286(39.6)$ & 0.08 \\
\hline No & $885(58.5)$ & $449(56.7)$ & $436(60.4)$ & \\
\hline
\end{tabular}

a Row \%, all other are column percentages for each variable. *Data from healthcare personnel.

Table 2. Care practice for smokers according to profession and smoking status

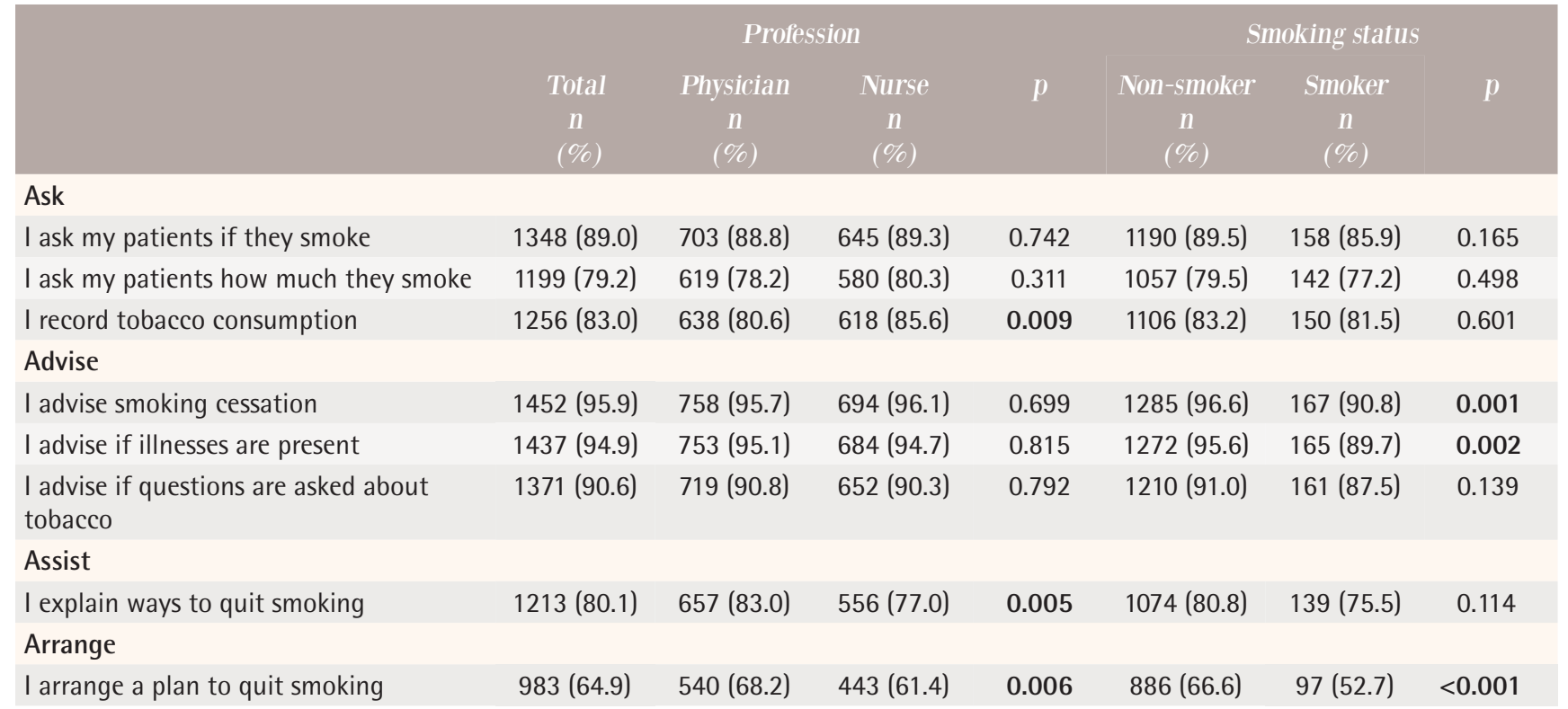


Table 3. Care practice for smokers according to level of knowledge and training

\begin{tabular}{|c|c|c|c|c|c|c|c|}
\hline & & Sufficient & owledge & & & icient traini & \\
\hline & $\begin{array}{c}\text { Total } \\
n \\
(\%)\end{array}$ & $\begin{array}{c}\text { Yes } \\
n \\
(\%)\end{array}$ & $\begin{array}{c}\text { No } \\
n \\
(\%)\end{array}$ & $p$ & $\begin{array}{c}\text { Yes } \\
n \\
(\%)\end{array}$ & $\begin{array}{c}\text { No } \\
n \\
(\%)\end{array}$ & $p$ \\
\hline Ask & & & & & & & \\
\hline I ask my patients if they smoke & $1348(89.0)$ & 729 (93.7) & $619(84.1)$ & $<0.001$ & $594(94.4)$ & 754 (85.2) & $<0.001$ \\
\hline I ask my patients how much they smoke & 1199 (79.2) & 667 (85.7) & $532(72.3)$ & $<0.001$ & $54(87.1)$ & $651(73.6)$ & $<0.001$ \\
\hline I record tobacco consumption & $1256(83.0)$ & $690(88.7)$ & 566 (76.9) & $<0.001$ & $57(90.8)$ & 685 (77.4) & $<0.001$ \\
\hline Advise & & & & & & & \\
\hline I advise smoking cessation & 1452 (95.9) & $759(97.6)$ & $693(94.2)$ & $<0.001$ & $620(98.6)$ & $832(94.0)$ & $<0.001$ \\
\hline I advise if illnesses are present & 1437 (94.9) & 750 (96.4) & 687 (93.3) & $<0.007$ & $614(97.6)$ & 823 (93.0) & $<0.001$ \\
\hline $\begin{array}{l}\text { I advise if questions are asked about } \\
\text { tobacco }\end{array}$ & $1371(90.6)$ & $738(94.9)$ & $633(86.0)$ & $<0.001$ & 597 (94.9) & $774(87.5)$ & $<0.001$ \\
\hline Assist & & & & & & & \\
\hline I explain ways to quit smoking & $1213(80.1)$ & 705 (90.6) & $508(69.0)$ & $<0.001$ & 577 (91.7) & 636 (71.9) & $<0.001$ \\
\hline Arrange & & & & & & & \\
\hline I arrange a plan to quit smoking & $983(64.9)$ & $625(80.3)$ & $358(48.6)$ & $<0.001$ & $526(83.6)$ & 457 (51.6) & $<0.001$ \\
\hline
\end{tabular}

Table 4. The main barriers perceived in primary care regarding smoking cessation management

$\begin{array}{lccc}\text { Barriers } & \text { Agree } & \text { Disagree } & \text { Mean } \pm \text { SD } \\ \text { Lack of time } & \% & 45.5 & 3.94 \pm 1.08 \\ \text { Scarcity of resources (material, etc.) } & 55.5 & 59.1 & 3.44 \pm 1.08 \\ \text { Organizational problems (schedule, etc.) } & 40.9 & 51.6 & 3.65 \pm 1.08 \\ \text { Insufficient training } & 48.4 & 64.6 & 3.19 \pm 1.17 \\ \text { No specialized care available to refer smokers to } & 35.4 & 72.2 & 2.95 \pm 1.25 \\ \text { Registry problems with the online platform } & 27.8 & 86.5 & 2.48 \pm 1.08\end{array}$

management in all the variables compared to those who did not $(\mathrm{p}<0.005)$. The same occurred with those who had received specific training in smoking cessation $(\mathrm{p}<0.001)$.

Psychological therapy was the most common intervention $(35.3 \%)$ whilst medication was prescribed by $31.5 \%$ (varenicline $19.4 \%$, nicotine replacement therapy $15.7 \%$, and bupropion $7.2 \%$ ).

Lack of time was the major barrier followed by problems of organization. In addition, one third of the participants considered insufficient training to be an issue (Table 4).

Table 5 depicts the relationship between the complex variable GP (GOLD) and the other variables. GP was carried out by $48.6 \%$ of the
Table 5. Factors associated with Good Practice (GOLD) in care for smokers (bivariant analysis) $(\mathrm{N}=1514)$

\begin{tabular}{|c|c|c|c|}
\hline Factors & $\begin{array}{c}\text { Good } \\
\text { Practice } \\
736(48.6 \%)\end{array}$ & $\begin{array}{c}\text { Improvable } \\
\text { Practice } \\
778(51.4 \%)\end{array}$ & $p$ \\
\hline Age (years), mean $\pm S D$ & $50.6 \pm 9.1$ & $50.4 \pm 10.4$ & 0.68 \\
\hline \multirow[t]{2}{*}{$\begin{array}{l}\text { Years of employment, } \\
\text { mean } \pm S D\end{array}$} & $19.3 \pm 9.2$ & $17.5 \pm 10.8$ & $<0.05$ \\
\hline & $n(\%)$ & $n(\%)$ & \\
\hline \multicolumn{4}{|l|}{ Sex } \\
\hline Male (367) & $168(45.8)$ & $199(54.2)$ & \multirow{2}{*}{0.21} \\
\hline Female (1147) & 568 (49.5) & 579 (50.5) & \\
\hline
\end{tabular}


Table 5. Continued

\begin{tabular}{|c|c|c|c|}
\hline Factors & $\begin{array}{c}\text { Good } \\
\text { Practice } \\
736(48.6 \%)\end{array}$ & $\begin{array}{c}\text { Improvable } \\
\text { Practice } \\
778(51.4 \%)\end{array}$ & $p$ \\
\hline \multicolumn{4}{|l|}{ Age group (years) } \\
\hline$<45(407)$ & $186(45.7)$ & $221(54.3)$ & \multirow{3}{*}{0.035} \\
\hline $45-55$ (467) & $250(53.5)$ & $217(46.5)$ & \\
\hline$>55(640)$ & $300(46.9)$ & $340(53.1)$ & \\
\hline \multicolumn{4}{|c|}{ Years of employment } \\
\hline$<10(325)$ & $114(35.1)$ & $211(64.9)$ & \multirow{3}{*}{$<0.001$} \\
\hline $10-19(451)$ & 238 (52.8) & $213(47.2)$ & \\
\hline$>19$ (733) & $383(52.3)$ & 350 (47.7) & \\
\hline \multicolumn{4}{|l|}{ Profession } \\
\hline Nurse (722) & $342(47.4)$ & $380(52.6)$ & \multirow{2}{*}{0.35} \\
\hline Physician (792) & $394(49.7)$ & $398(50.3)$ & \\
\hline \multicolumn{4}{|l|}{ Type of contract } \\
\hline Interim (243) & $134(55.1)$ & 109 (44.9) & \multirow{2}{*}{0.026} \\
\hline Permanent (1271) & $602(47.4)$ & $669(52.6)$ & \\
\hline \multicolumn{4}{|l|}{ Center location } \\
\hline Rural (424) & $210(49.5)$ & $214(50.5)$ & \multirow{2}{*}{0.66} \\
\hline Urban (1090) & $526(48.3)$ & $564(51.7)$ & \\
\hline \multicolumn{4}{|l|}{ Smoking status } \\
\hline Non-smoker (753) & $383(51.0)$ & $369(49.0)$ & \multirow{3}{*}{0.006} \\
\hline Ex-smoker (577) & $282(48.9)$ & $295(51.1)$ & \\
\hline Smoker (184) & $70(38.0)$ & $114(62.0)$ & \\
\hline \multicolumn{4}{|l|}{ Training } \\
\hline Sufficient (629) & $426(67.7)$ & $203(32.3)$ & \multirow{2}{*}{$<0.001$} \\
\hline Insufficient (885) & $310(35.0)$ & $575(65.0)$ & \\
\hline \multicolumn{4}{|l|}{ Knowledge } \\
\hline Sufficient (778) & $488(62.7)$ & $290(37.3)$ & \multirow{2}{*}{$<0.001$} \\
\hline Insufficient (736) & $248(33.7)$ & $488(66.3)$ & \\
\hline
\end{tabular}

participants and was associated with: years of employment (>10 years), age (between 45-55 years), being a non-smoker, having an interim contract, and sufficient levels of knowledge and training.

The logistic regression analysis (Table 6) depicts the association of GP with the following: interim contract, sufficient knowledge and training, female sex, smoking status, and $>10$ years employment.

\section{DISCUSSION}

We present here the results from a Spanish population study composed of a representative sample of PC physicians and nurses. With respect to the care of smokers, GP was observed in only $48.6 \%$ and corresponded to being a non-smoker and having a high level of knowledge and training, and, to a lesser extent, being female, an ex-smoker, and with a work experience $>10$ years. The main barriers for GP were lack of time and problems of organization; only $35.4 \%$ of the participants mentioned insufficient training as a barrier.

\section{Comparison with other studies}

The minor difference between physicians and nurses with respect to GP (49.7\% vs $47.4 \%$ ) could be partially explained by the latter's greater consumption of tobacco (13.2\%). A finding that concurs with another study performed in Spain ${ }^{12}$, and also one in Bosnia with a markedly greater prevalence of smoking in nurses ${ }^{13}$. Such results have been confirmed by a systematic review carried out in $2017^{14}$. Moreover, a

Table 6. Variables related to Good Practice (univariate and multivariate logistic regression analysis)

$\begin{array}{llll}\text { Variables (Reference group) } & & \text { OR }(95 \% \text { CI }) & 1.344(1.039-1.739) \\ \text { Sex (Male) } & \text { Female } & 1.162(0.918-1.471) & 1.222(0.964-1.550) \\ \text { Age group (<45 years) } & 45-55 & 1.369(1.048-1.787) & 0.852(0.598-1.214) \\ \text { Years of employment }(<10) & >55 & 1.048(0.817-1.345) & 1.418(1.032-1.950) \\ & 10-19 & 2.068(1.542-2773) & 1.672(1.239-2.257) \\ \text { Contract (Permanent) } & >19 & 2.025(1.546-2.653) & 1.478(1.082-2.017) \\ \text { Centre (Urban) } & \text { Interim } & 1.366(1.037-1.800) & 0.908(0.711-1.160) \\ \text { Smoking status (Smoker) } & \text { Rural } & 1.052(0.841-1.317) & 1.801(1.263-2.568) \\ & \text { Non-smoker } & 1.695(1.218-2.358) & 1.471(1.024-2.113) \\ \text { Training (Insufficient) } & \text { Ex-smoker } & 1.557(1.109-2.186) & 2.444(1.829-3.267) \\ \text { Knowledge (Insufficient) } & \text { Sufficient } & 3.892(3.134-4.835) & 1.862(1.399-2.478)\end{array}$

AOR: adjusted odds ratio. $\mathrm{Cl}$ : confidence interval. 
number of qualitative studies have reported the effect on GP of negative sensations of guilt and discomfort associated with being a smoker ${ }^{15,16}$.

A study performed in Switzerland reported a GP level of $85 \%$. Nevertheless, it employed different variables and the percentage of smokers was greater, thus it is not strictly comparable. It did coincide, however, in that good training was related to better practice ${ }^{17}$. Regarding 5As strategy, research in Italy with 722 PC physicians (13.4\% smokers) found similar results $-83.4 \%$ and $93.7 \%$ for Ask and Advise, respectively ${ }^{18}$.

In contrast to our findings, a review in $2016^{19}$ described considerable discrepancies among the different elements that make up GP with regard to PC physicians. From the 35 articles that were included, the following was observed: $65 \%$ Ask, $63 \%$ Advise, 36\% Assess, 44\% Asist, and only 22\% Arrange (follow-up).

In a study performed in Argentina with 254 physicians it was observed that $90 \%$ asked about tobacco consumption and $44 \%$ prescribed pharmacologic treatment, both practices related to the training received $(\mathrm{OR}=6.5 \text {; 95\% CI: } 2.2-19.1)^{20}$. A finding that was also evaluated among 456 PC professionals in Jordan, which showed that $51.4 \%$ asked about smoking and $50.5 \%$ advised cessation. Nevertheless, only $23.7 \%$ evaluated willingness to give up smoking, and a mere $17.9 \%$ explained different counselling options ${ }^{21}$.

\section{Differences according to gender}

A 2018 study performed in Greece with physicians (25\% smokers) found a relationship between female gender and better application of the $5 \mathrm{As}$ recommendations ( $\mathrm{OR}=3.38$; 95\% CI: $1.11-10.35)$, which coincides with our results $(\mathrm{OR}=1.3 ; 95 \%$ CI: $1.03-1.7)^{22}$. It also reported that expert referrals were more common (46\%) in the case of female professionals $^{23}$.

\section{Differences between smokers and non-smokers}

A meta-analysis carried out by Duaso et al. ${ }^{24}$ observed that physicians who smoked had a $17 \%$ greater risk of not recommending their patients to give up smoking $(\mathrm{RR}=0.83 ; 95 \% \mathrm{CI}: 0.77-0.90)$, and remission in cessation programmes was more probable $(\mathrm{RR}=1.40$; 95\% CI: $1.09-1.79)^{24}$.
An international study in 2009 composed of 2836 PG physicians from 16 countries reported a better GP profile among non-smokers: they asked patients more frequently about their smoking habits ( $85.0 \%$ vs $80.3 \%$ ), carried out a better registration of consumption ( $70.0 \%$ vs $64.0 \%$ ), gave more advice ( $89.9 \%$ vs $84.4 \%)$, agreed on more follow-up (48.5\% vs $39.8 \%$ ), and prescribed more medication for smoking cessation $(30.6 \% \text { vs } 23.3 \%)^{25}$. All of which concur with our results.

\section{Barriers to assistance}

According to our data, PC physicians and nurses consider the greatest barriers to be lack of time, problems of organization, and scarcity of resources, and, to a lesser extent, insufficient training. With respect to our environment, in 2005 we had already reported lack of time, low patient motivation, and the need for specific training ${ }^{26}$. In 2016, in Argentina ${ }^{20}$ lack of time and training were also described as the main barriers. Some authors ${ }^{21}$ additionally mentioned scarcity of resources and insufficient institutional support, data that were confirmed in Holland where different medical specialities are included in smoking cessation programmes ${ }^{27}$.

\section{Training for healthcare workers}

The relationship between skills and GP has been widely covered in the literature and in varying environments $^{13,18,23,26}$. A 2012 Cochrane review ${ }^{28}$ demonstrated that the training of PC personnel could enhance continued ( $\mathrm{OR}=1.6$; 95\% CI: 1.26-2.03) and sporadic abstinence $(\mathrm{OR}=1.36$; $95 \%$ CI: $1.2-$ 1.55 ), and frequency of questions about the date of cessation. It could also lead to more advice and selfhelp material being offered, and assist in establishing a cessation date.

\section{Other considerations}

A 2019 study based on the Eurobarometer ${ }^{29}$ reported that between 2012 and 2017 the number of individuals who attempted to cease smoking without any help increased (70.3\% vs $74.8 \%$ ) whilst the use of pharmacotherapy and cessation services decreased ( $14.6 \%$ vs $11.1 \%$ and $7.5 \%$ vs $5.0 \%$, respectively). In addition, it found that those who resided in countries with integral cessation policies had a greater probability of employing pharmacotherapy $(\mathrm{OR}=1.78$; 
95\% CI: 1.15-2.76) and smoking cessation services $(\mathrm{OR}=3.44$; 95\% CI: $1.78-6.66)$ compared to countries with weak policies ( $\mathrm{OR}=2.27 ; 95 \% \mathrm{CI}: 1.27-4.06)$. It should be remembered that from 1 January 2020, the Spanish Healthcare system has financed two smoking cessation drugs, which represents a milestone in achieving better results in the general population.

\section{Limitations and strengths}

Our study analyzes certain characteristics of PC physicians and nurses that influence GP in smoking cessation management. Nevertheless, in addition to such issues as standardizing clinical registers and/ or integrated electronic protocols, aspects related to the patients themselves (e.g. pathologies and intrinsic motivation) could also play a role. One limitation is that it has not been possible to identify information about willingness to quit (Assess), although it does partially appear in the question related to 'Agreeing a plan to give up smoking'. In addition, we should take into account the flaws inherent in employing questionnaires ${ }^{30}$. Nevertheless, the greatest strengths of our study are its representativeness, broad geographical area, sample size, and inclusion of both medical and nursing staff.

\section{CONCLUSIONS}

In our study, the Good Practice of public healthcare physicians and nurses is related to non-smoking, and suitable training and knowledge. The barriers to its improvement are lack of time and problems of organization. It is clear that training activities are needed within the Spanish National Health Service, with support from scientific societies, in order to prioritize care for the smoker.

\section{REFERENCES}

1. Okuyemi KS, Nollen NL, Ahluwalia JS. Interventions to facilitate smoking cessation. Am Fam Physician 2006;74(2):262-271. PMID:16883923.

2. Poon VH. Practice tips. Model for counseling people in relationships. Can Fam Physician. 2007;53(2):237-238. PMID:17872640.

3. Fiore MC, Jaen C, Baker T, et alt. Treating Tobacco Use and Dependence: 2008 Update. Clinical Practice Guideline. Rockville, MD: US Department of Health and Human Services Public Health Service; 2008.

4. U.S. Preventive Services Task Force. Counseling and interventions to prevent tobacco use and tobacco-caused disease in adults and pregnant women: U.S. Preventive
Services Task Force reaffirmation recommendation statement. Ann Intern Med. 2009;150(8):551-555. doi:10.7326/0003-4819-150-8-200904210-00009

5. World Health Organization. WHO Report on the Global Tobacco Epidemic, 2019: Offer help to quit tobacco use. https://apps.who.int/iris/bitstream/han dle/10665/326043/9789241516204-eng.pdf?ua=1 . Published 2019. Accessed July 27, 2020.

6. Stead LF, Buitrago D, Preciado N, Sanchez G, Hartmann-Boyce J, Lancaster T. Physician advice for smoking cessation. Cochrane Database Syst Rev. 2013;(5):CD000165. doi:10.1002/14651858.CD000165. pub4

7. Cahill K, Lancaster T, Green N. Stage-based interventions for smoking cessation. Cochrane Database Syst Rev. 2010;(11):CD004492. doi:10.1002/14651858. CD004492.pub4

8. Verbiest M, Brakema E, van der Kleij R, et al. National guidelines for smoking cessation in primary care: a literature review and evidence analysis. NPJ Prim Care Respir Med. 2017;27(1):2. doi:10.1038/s41533-0160004-8

9. Martin Cantera C, Puigdomenech E, Ballve JL, et al. Effectiveness of multicomponent interventions in primary healthcare settings to promote continuous smoking cessation in adults: a systematic review. BMJ Open. 2015;5(10):e008807. doi:10.1136/ bmjopen-2015-008807

10. Papadakis S, McDonald P, Mullen KA, Reid R, Skulsky $\mathrm{K}$, Pipe A. Strategies to increase the delivery of smoking cessation treatments in primary care settings: a systematic review and meta-analysis. Prev Med. 2010;51(3-4):199213. doi:10.1016/j.ypmed.2010.06.007

11. Iglesias Sanmartin JM, Furio Martinez A, Clemente Jimenez L, et al. Attitudes towards anti-smoking legislation and prevalence of tobacco consumption in Spanish primary healthcare personnel. Tob Prev Cessation. 2019;5(March). doi:10.18332/tpc/104434

12. Jimenez-Ruiz CA, Riesco Miranda JA, Ramos PA, et al. Prevalence of and Attitudes towards Smoking among Spanish Health Professionals. Respiration. 2015;90(6):474-480. doi:10.1159/000441306

13. Hodgetts G, Broers T, Godwin M. Smoking behaviour, knowledge and attitudes among Family Medicine physicians and nurses in Bosnia and Herzegovina. BMC Fam Pract. 2004;5:12. doi:10.1186/1471-2296-5-12

14. Duaso MJ, Bakhshi S, Mujika A, Purssell E, While AE. Nurses' smoking habits and their professional smoking cessation practices. A systematic review and metaanalysis. Int J Nurs Stud. 2017;67:3-11. doi:10.1016/j. ijnurstu.2016.10.011

15. Gonzalez S, Bennasar M, Pericas J, Segui P, De PJ. Spanish primary health care nurses who are smokers: this influence on the therapeutic relationship. Int Nurs Rev. 2009;56(3):381-386. doi:10.1111/j.1466- 


\subsubsection{9.x}

16. Mujika A, Arantzamendi M, Lopez-Dicastillo O, Forbes A. Health professionals' personal behaviours hindering health promotion: A study of nurses who smoke. J Adv Nurs. 2017;73(11):2633-2641. doi:10.1111/jan.13343

17. Jacot SI, Ruffieux C, Cornuz J. Self-reported smoking cessation activities among Swiss primary care physicians. BMC Fam Pract. 2009;10(1):22. doi:10.1186/1471-2296$10-22$

18. Nobile CG, Bianco A, Biafore AD, Manuti B, Pileggi C, Pavia M. Are primary care physicians prepared to assist patients for smoking cessation? Results of a national Italian cross-sectional web survey. Prev Med. 2014;66:107-112. doi:10.1016/j.ypmed.2014.06.009

19. Bartsch AL, Harter M, Niedrich J, Brutt AL, Buchholz A. A Systematic Literature Review of Self-Reported Smoking Cessation Counseling by Primary Care Physicians. PLoS One. 2016;11(12):e0168482. doi:10.1371/journal. pone.0168482

20. Schoj V, Mejia R, Alderete M, et al. Use of Smoking Cessation Interventions by Physicians in Argentina. J Smok Cessat. 2016;11(3):188-197. doi:10.1017/ jsc.2014.24

21. Matouq A, Khader Y, Khader A, et al. Knowledge, attitude, and behaviors of health professionals towards smoking cessation in primary healthcare settings. Transl Behav Med. 2018;8(6):938-943. doi:10.1093/tbm/ibx045

22. Papadakis S, Girvalaki C, Vardavas C, et al. Factors associated with rates of tobacco treatment delivery by General Practitioners in Greece: Missed opportunities for prevention?. Tob Induc Dis. 2018;16(May). doi:10.18332/ tid/90822

23. Schnoll RA, Rukstalis M, Wileyto EP, Shields AE. Smoking Cessation Treatment by Primary Care Physicians: An Update and Call for Training. Am J Prev Med. 2006;31(3):233-239. doi:10.1016/j.amepre.2006.05.001

24. Duaso MJ, McDermott MS, Mujika A, Purssell E, While A. Do doctors' smoking habits influence their smoking cessation practices? A systematic review and meta-analysis. Addiction. 2014;109(11):1811-1823. doi:10.1111/add.12680

25. Pipe A, Sorensen M, Reid R. Physician smoking status, attitudes toward smoking, and cessation advice to patients: an international survey. Patient Educ Couns. 2009;74(1):118-123. doi:10.1016/j.pec.2008.07.042

26. Cerrada EC, Olmeda CL, Senande EB, Rodriguez BG, Sanz CT. [Views, practices, barriers, and the will to change, when counselling to give up smoking is being given]. Aten Primaria. 2005;36(8):434-441. doi:10.1157/13081057

27. Meijer E, Van der Kleij RMJJ, Chavannes NH. Facilitating smoking cessation in patients who smoke: a large-scale cross-sectional comparison of fourteen groups of healthcare providers. BMC Health Serv Res. 2019;19(1):750. doi:10.1186/s12913-019-4527-x

28. Carson KV, Verbiest ME, Crone MR, et al. Training health professionals in smoking cessation. Cochrane Database Syst Rev. 2012;(5):CD000214. doi:10.1002/14651858. CD000214.pub2

29. Filippidis FT, Laverty AA, Mons U, Jimenez-Ruiz C, Vardavas CI. Changes in smoking cessation assistance in the European Union between 2012 and 2017: pharmacotherapy versus counselling versus e-cigarettes. Tob Control. 2019;28(1):95-100. doi:10.1136/ tobaccocontrol-2017-054117

30. Diaz V. Problemas de representatividad en las encuestas con muestreos probabilisticos. Papers. 2004;74:45-66. doi:10.5565/rev/papers/v74n0.1081

\section{ACKNOWLEDGEMENTS}

We sincerely thank all our colleagues from the Spanish Primary Care Centers for their collaboration with the publication of this article. Publication of the manuscript has been possible thanks to the Spanish Family and Community Medical Society (semFYC) and its federated societies.

\section{CONFLICTS OF INTEREST}

The authors have each completed and submitted an ICMJE form for disclosure of potential conflicts of interest. The authors declare that they have no competing interests, financial or otherwise, related to the current work.

\section{FUNDING}

There was no source of funding for this research.

\section{PROVENANCE AND PEER REVIEW}

Not commissioned; externally peer reviewed. 